\title{
Rentaka A Car Rental Company
}

\author{
Mrs. Sangeeta Nagpure, Mohamed Taqi Mithani, Akash Mody, Mohammed Tahir, Hinal \\ Panchal
}

\begin{abstract}
A car rental is a company in which the customer can get a automobiles service for short duration, generally ranging from a few hours to a few weeks. It comprises of numerous local branches (which allow a user to avail a car at on location and return the same at a different location), and primarily located near airports or busy city areas and often complemented by a website allowing online reservations. Car rental service agencies primarily serve their customers who do not own their own car, travelers who are out of town, or owners of damaged or destroyed vehicles who are awaiting repair or insurance compensation. Rentaka offers an easily available service with a high usability quotient to ensure smooth transportation.
\end{abstract}

Index Terms - Car Rental, Door Security,Identification, Radio Frequency, Near Field Communication, Wallet, Web Application.

\section{INTRODUCTION}

In today's world with the growing population of India and with the busy schedule of people, commuting is the main problem for many citizens. Many of the users have cars and some who can't afford it, have to either travel by public transport or rent a car for their use. In this case if a person wants a car for certain amount of time till his commute to a place, but still will have to pay the rental company the price for the whole day.Rentaka tries to resolve this problem, by allowing its users to rent the cars for certain time as per their convenience.

In these papers [1] [2] [3], the author has proposed:

RFID - SmartCard based security system:

The proposed system will require a RFID reader attached to the car door. It uses a smart card which will be used as an RFID tag to authenticate users. This smart card has informa-tion stored in it which will be immediately read by the RFID Reader when it comes in its near field region. The Reader takes this information and matches it with the information stored in it. On successful match, the user will be allowed to enter otherwise not. The following demonstrates the working of RFID based Door locking mechanism. Methodology

Mrs.SangeetaNagpure, Department of Information Technology, K.J Somaiya College of Engineering, Mumbai77,India,

Mohamed TaqiMithani, Department of Information Technology, K.J Somaiya College of Engineering, Mumbai77,India,

Akash Mody, Department of Information Technology, K.J Somaiya College of Engineering, Mumbai77,India,

Mohammed Tahir, Department of Information Technology, K.J Somaiya College of Engineering, Mumbai77,India,

Hinal Panchal, Department of Information Technology, K.J Somaiya College of Engineering, Mumbai77,India,

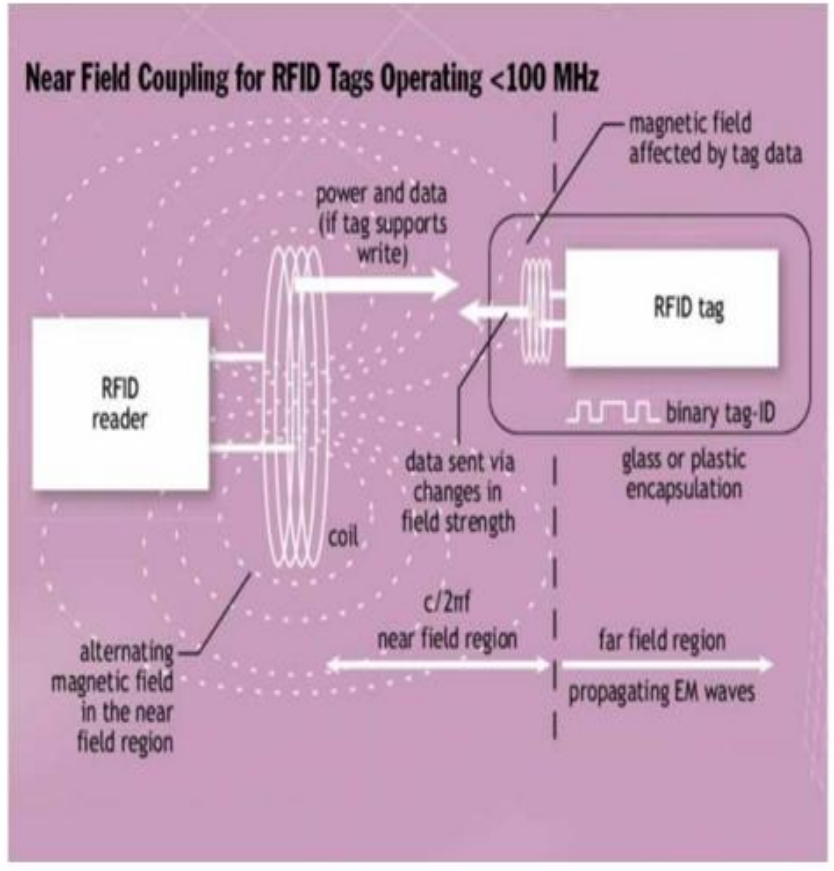

Fig. 1. RFID working Principle

\section{RELATED RESEARCH}

\section{A. Door Security}

Nowadays security is the most essential issue everywhere in the world; so security of everything gains higher and higher importance in recent years. Even in our context, the car door security gains utmost importance since it is the starting point of user interaction with the car. It is necessary to make sure that only authorized users be able to enter the car.

RFID systems operates from very low frequency (VLF) to extremely high frequency (EHF). RFID system operating in low frequency range make use of electromagnetic wave propagation to communicate their data and commands, these use passive tags. RFID systems operating in low frequency range operates on principle of near field coupling between tag

and reader. In near field RFID system, electromagnetic waves are transmitted by reader which propagates outwards with spherical wave front. Tags placed within field collect some energy. Then exchange of data between tag and reader takes place. The amount of energy available at any particular point is related to distance from the transmitter as expressed as $1 / \mathrm{d}$ where $\mathrm{d}$ is distance from the transmitter. 


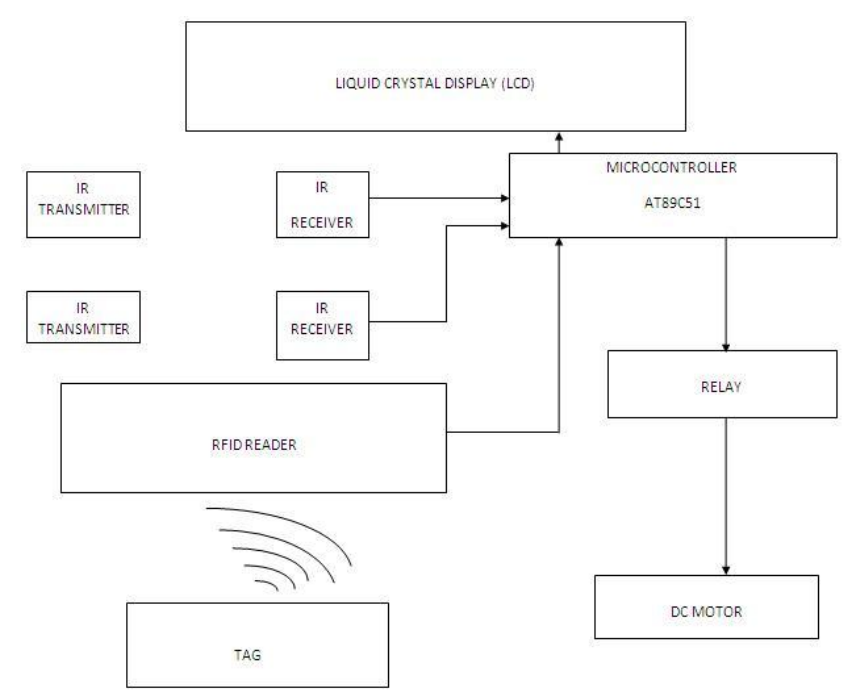

Fig. 2. RFID Block Diagram

RFID tag: A tag is the fundamental unit of operation. It consists of small chip and an antenna. Thechip contains useful information and antenna is used to activate the chip and communicate with reader.

RFID reader or interrogator: The reader emits a pulse of electro-magnetic waves to the tag and wait for tag's response. Upon detection, the tag returns a response that contains the tag's serial number and other information as well.

Power conversion circuits: Power conversion circuits al-low individual modules to make use of existing power supplies.

Microcontroller: Microcontroller to be used is AT89C51.

Relay: Relay used is of $5 \mathrm{~V}$.

\section{B. Existing System [6]}

Client will book the car using Web or Mobile app. Then the client gets the available at the centre near a particular area the clients will have to go to the centre to pick up the car. The booking of the car is per day/ hour/months.

\section{PROPOSED SYSTEM}

In this paper, we propose an anonymous car rental service based on NFC technology and/or remote authentication using smart card. Our main features include:

Anonymity: Users provide their personal information to the app only. The car companies cannot get users real identity.

Self-drive: Users enjoy a seamless driving experience across a wide range of luxury cars.

RFID Smart Card: Users will be provided with app-associated smart cards which will be used for authen-tication.
Trace ability: If there are customer disputes or accidents, the rental company can track the users whereabouts.

Flexibility: Users are free to choose their preferred vehi-cle.

A customer has to register his identity via the app (or web-app) on his NFC phone. This registration should be also accompanied with license registration and verification against the drivers database. The customer should request a temporary anonymous personal identification number (pin) from the app whenever he desires to avail the services. If the license is valid, the company issues the pin for the requested vehicle to the user over the app. The vehicle authenticates the user through his/her NFC phone/smart card. Last, after the user is authenticated, the he/she is allowed to drive the car. When a car is returned, the rental company can collect the charges through a TTP (Trusted Third Party) or the built-in wallet facility. If customer disputes arise or there are accidents, the authorities can request to reveal the users identity.

\section{A. Database}

In order to validate the Drivers Credentials, we need data of all drivers from all areas across the region(city). Also, to simplify the process, we aim to generate our own dataset containing relevant features - name, licence number, driver history, age, etc... - using available technologies like python, excel, etc.

Last but not the least, a dataset that contains all the rfid keys which can be associated with the drivers primary keys (personal identification numbers for drivers registered with our app) is required which will provide the valid rfid tag id to the rfid reader on the car door (this will be used for unlocking the car door). This dataset also contains the passwords for the Key holder terminal discussed above which will open on entering the correct password provided through this data.

\begin{tabular}{|c|c|c|c|c|c|c|c|}
\hline & A. & B & c: & p & E: & E. & 9 \\
\hline \% & STÁT: & CITV & YEAR_ISSUED & DRIVER ID: & LNO & VÁLIDTILLL & DOB \\
\hline 2 & MH & 12 & 2016 & 8201130 & MH1220168201130 & $2036 / 02 / 05$ & 1997/10/11 \\
\hline 3 & $\mathrm{MH}$ & 13 & 2002 & 1719325 & MH1320021719325 & $2022 / 12 / 11$ & $2008 / 06 / 29$ \\
\hline is & $\mathrm{MH}$ & 14 & 2017 & 6229460 & MH1420176229460: & $2037 / 01 / 10$ & $2007 / 04 / 11$ \\
\hline 素 & $\mathrm{MH}$ & 13 & 2000 & 0284037. & MH1320000284037. & $2020 / 01 / 09$ & $1994 / 10 / 13$ \\
\hline 3 & MH: & 14 & 2017 & 8963143 & MH1420178963143, & $2037 / 09 / 16$ & $1995 / 09 / 30$ \\
\hline a & MH & 12 & 2012 & 5084459 & MH1220125084459 & $2032 / 12 / 09$ & $1994 / 05 / 22$ \\
\hline i & $\mathrm{MH}$ & 13 & 2008 & 0565270 & MH1320080565270 & $2028 / 05 / 16$ & $2005 / 10 / 16$ \\
\hline \% & $\mathrm{MH}$ & 12 & 2003 & 6763277 & МH12200367632777 & $2023 / 08 / 09$ & . $1991 / 07 / 15$ \\
\hline : & MH & 13 & 2013 & 8507774 & MH1320138507774 & $2033 / 01 / 10$ & $1996 / 04 / 14$ \\
\hline 78 & $\mathrm{MH}$ & 14 & 2005 & 2014325 & MH1420052014325 & $2025 / 02 / 15$ & $1990 / 05 / 18$ \\
\hline (i) & $\mathrm{MH}$ & 14 & 2018 & 6380877 & MH1420186380877 & $2038 / 10 / 30$ & $2007 / 03 / 26$ \\
\hline *3: & $\mathrm{MH}$ & 13 & 2003 & 7041015 & MH1320037041015 & $2023 / 11 / 16$ & $1992 / 08 / 26$ \\
\hline 4: & MH & 13 & 2019 & 6751302 & MH1320196751302 & $2039 / 03 / 30$ & 1994/01/24 \\
\hline 95: & MH & 18 & 2007: & 5294340 & MH1320075294340 & $2027 / 07 / 24$ & $2002 / 02 / 22$ \\
\hline 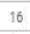 & $\mathrm{MH}$ & 12 & 2019 & 3868245 & MH1220193868245 & $2039 / 05 / 10$ & $1997 / 06 / 17$ \\
\hline it? & $\mathrm{MH}$ & 14 & 2002 & 9420428 & MH1420029420428 & $2022 / 05 / 22$ & $2008 / 12 / 24$ \\
\hline 9อ: & $\mathrm{MH}$ & 13 & 2005 & 0114728 & MH1320050114728 & $2025 / 12 / 10$ & $1998 / 05 / 06$ \\
\hline 19:" & $\mathrm{MH}$ & 12 & 2010 & 5945066 & MH1220105945066 & $2030 / 11 / 16$ & $1998 / 05 / 12$ \\
\hline 20: & $\mathrm{MH}$ & 14 & 2000 & 0316489 & MH1420000316489. & $2020 / 03 / 01$ & $1998 / 02 / 28$ \\
\hline $2 \pi$ & $\mathrm{MH}$ & 12 & 2005 & 4465784 & MH1220054465784 & $2025 / 07 / 25$ & $2006 / 11 / 12$ \\
\hline in. & $\mathrm{MH}$ & 13 & 2014 & 9962028 & MH1320149962028 & $2034 / 04 / 17$ & $1991 / 04 / 25$ \\
\hline 20: & MH & 18 & 2017 & 8264613 & МH1320178264613 & $2037 / 02 / 12$ & $2000 / 10 / 09$ \\
\hline 24: & $\mathrm{MH}$ & 12 & 2011 & 8271452 & MH1220118271452 & $2031 / 11 / 22$ & $1998 / 04 / 22$ \\
\hline
\end{tabular}

Fig. 3. RTO Database1 


\begin{tabular}{|c|c|c|c|c|c|c|c|}
\hline & A & 8 & c & D & E & $\mathrm{F}$ & G \\
\hline 9421 & $\mathrm{DL}$ & 13 & 2020 & 5376411 & DL1320205376411 & $2040 / 10 / 20$ & $1992 / 07 / 20$ \\
\hline 9422 & $\mathrm{DL}$ & 12 & 2009 & 9314639 & DL1220099314639 & $2029 / 07 / 04$ & $2008 / 06 / 08$ \\
\hline 9423 & $\mathrm{DL}$ & 14 & 2018 & 5962063 & DL1420185962063 & $2038 / 06 / 13$ & $2003 / 06 / 19$ \\
\hline 9424 & $\mathrm{DL}$ & 12 & 2003 & 0670082 & DL1220030670082 & $2023 / 01 / 04$ & $2010 / 02 / 27$ \\
\hline 9425 & $\mathrm{DL}$ & 12 & 2018 & 9408260 & DL1220189408260 & $2038 / 11 / 24$ & $1998 / 05 / 04$ \\
\hline 9426 & $\mathrm{DL}$ & 14 & 2016 & 0344732 & DL1420160344732 & $2036 / 05 / 03$ & $1998 / 02 / 26$ \\
\hline 9427 & $\mathrm{DL}$ & 12 & 2008 & 2880111 & DL1220082880111 & $2028 / 04 / 05$ & $1994 / 04 / 28$ \\
\hline 9428 & $\mathrm{DL}$ & 12 & 2008 & 7552242 & DL1220087552242 & $2028 / 09 / 08$ & $1995 / 04 / 14$ \\
\hline 9429 & $\mathrm{DL}$ & 12 & 2014 & 2751591 & DL1220142751591 & $2034 / 10 / 08$ & $2010 / 11 / 17$ \\
\hline 9430 & $\mathrm{DL}$ & 14 & 2004 & 4830560 & DL1420044830560 & $2024 / 01 / 09$ & $1999 / 10 / 04$ \\
\hline 9431 & $\mathrm{DL}$ & 14 & 2005 & 7650528 & DL1420057650528 & $2025 / 06 / 24$ & $2005 / 03 / 28$ \\
\hline 9432 & $\mathrm{DL}$ & 12 & 2019 & 6027690 & DL1220196027690 & $2039 / 01 / 02$ & $1993 / 08 / 14$ \\
\hline 9433 & $\mathrm{DL}$ & 12 & 2007 & 3764052 & DL1220073764052 & $2027 / 01 / 18$ & $2006 / 06 / 04$ \\
\hline 9434 & $\mathrm{DL}$ & 13 & 2009 & 1300346 & DL1320091300346 & $2029 / 07 / 19$ & $1991 / 05 / 02$ \\
\hline 9435 & $\mathrm{DL}$ & 12 & 2003 & 3130790 & DL1220033130790 & $2023 / 03 / 22$ & $2003 / 08 / 22$ \\
\hline 9436 & $\mathrm{DL}$ & 14 & 2010 & 9382659 & DL1420109382659 & $2030 / 03 / 19$ & $2008 / 09 / 04$ \\
\hline 9437 & $\mathrm{DL}$ & 14 & 2006 & 8263994 & DL1420068263994 & $2026 / 08 / 27$ & $2007 / 03 / 08$ \\
\hline 9438 & $\mathrm{DL}$ & 12 & 2013 & 6049237 & DL1220136049237 & $2033 / 09 / 20$ & $1990 / 04 / 09$ \\
\hline 9439 & $\mathrm{DL}$ & 14 & 2006 & 4326522 & DL1420064326522 & $2026 / 11 / 05$ & $1991 / 06 / 30$ \\
\hline 9440 & $\mathrm{DL}$ & 12 & 2013 & 1580077 & DL1220131580077 & $2033 / 10 / 15$ & $2005 / 12 / 15$ \\
\hline 9441 & $\mathrm{DL}$ & 14 & 2016 & 3989277 & DL1420163989277 & $2036 / 11 / 14$ & $2007 / 01 / 20$ \\
\hline 9442 & $\mathrm{DL}$ & 12 & 2009 & 8819745 & DL1220098819745 & $2029 / 07 / 23$ & $2004 / 03 / 17$ \\
\hline 9443 & $\mathrm{DL}$ & 13 & 2003 & 7637501 & DL1320037637501 & $2023 / 08 / 08$ & $2003 / 12 / 15$ \\
\hline 9444 & $\mathrm{DL}$ & 13 & 2014 & 2509510 & DL1320142509510 & $2034 / 05 / 01$ & $2003 / 02 / 25$ \\
\hline
\end{tabular}

Fig. 4. RTO Database2

\section{B. Google API}

In order to view view the cars nearby the user, and book the one nearest. The functionality is such that if the user click on the car pin in the map,it will redirect the user to the booking page. After the booking is done, it will generate a receipt Locations of the cars are updated on the database which extracted by a PHP script, which will call the XML-marker file which shows the cars on the google map.

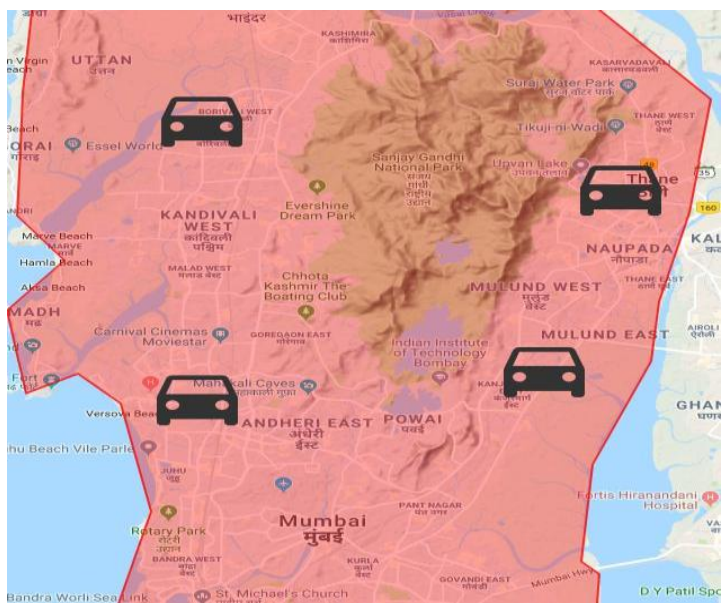

\section{RESULT}

A google form had been circulated to the public with the hosted web-application link.The response of $60 \%$ to $70 \%$ was achieved.



Fig. 6. Results

\section{CONCLUSION}

Hence, we conclude saying that we collectively aim at providing a delightful driving experience to users who cannot afford to get a car of their own, also to users thriving at experiencing a wide variety of automobiles, or to simply anyone in need of a car for transportation purposes. We also want to take the car rental definition to another level by making our cars available to users whenever and wherever they want.

\section{REFERENCES}

[1] Pradnya R. Nehete, J. P. Chaudhari, S. R. Pachpande, K. P. Rane Literature Survey on Door Lock Security Systems. International Journa of Computer Applications (0975 8887)Volume 153 No2, November 2016

[2] Won Jay SONG and Byung Ha AHN, PKI-Based Security and Privacy Controls Using Synchronized 2-Way Double-Type Smartcard Terminals for Healthcare Information Access Systems Engineering and Operations Research Labs, Department of Mechatronics, KwangJu Institute of Sci-ence and Technology.

[3] Hakim. L. Fourar, A Remote Authentication Model Using Smart Cards, CIS Lab, Prince Sultan University.

[4] Sukhraj Singh, Neeraj Kumar, Navjot Kaur, Design and Development Of RFID Based Intelligent Security System. International Journal of Ad-vanced Research in Computer Engineering and Technology (IJARCET), Volume 3 Issue 1, January 2014.

[5] Jie-Ci Yang, Chin-Lun Lai, Hsin-Teng Sheu, Jiann-Jone Chen, An In-telligent Automated Door Control System Based on a Smart Camera, www.mdpi.com/journal/sensors, 2013.

[6] https://www.zoomcar.com/mumbai

[7] https://en.wikipedia.org/wiki/Car rental 